\title{
Influencia del virus GLRV en la composición polifenólica de vinos de Vitis vinífera cv. Bonarda en Mendoza, Argentina
}

\author{
Laura Germano $^{3}$, David Cobos ${ }^{2,3, \text { a }}$, Emiliano Malovini ${ }^{1,2}$, Daniela Marmili ${ }^{3}$, Yésica Baldo ${ }^{3}$ y Juan Cavagnaro ${ }^{1,2}$ \\ ${ }^{1}$ Instituto de Biología Agrícola Mendoza, CONICET \\ ${ }^{2}$ Cátedra de Fisiología Vegetal, Facultad de. Ciencias. Agrarias, Universidad Nacional de Cuyo \\ ${ }^{3}$ Instituto Nacional de Vitivinicultura San Martín 430, Ciudad Mendoza (CP 5500), Argentina
}

\begin{abstract}
Resumen. El Virus Grape Leaf Roll Virus (GLRV) afecta la Vid. Disminuye la superficie foliar, clorofila, y capacidad fotosintética, ocasionando disminuciones de hasta un $70 \%$ en la producción de uvas, retardo en la maduración, disminución del contenido de azúcares, y alteraciones en el color de las bayas. Objetivo: establecer y cuantificar la incidencia de los virus presentes en los viñedos mendocinos sobre la calidad y composición polifenólica de sus vinos. Se seleccionó la variedad Bonarda, de ciclo vegetativo largo. Hipótesis: el ataque de virus en plantas generará uvas de menor concentración de azúcares y vinos con menor graduación alcohólica, disminución en el color y modificará el perfil de antocianas. Se realizó un muestreo dirigido, seleccionando viñedos en 4 oasis productivos de Mendoza. Se seleccionaron plantas con síntomas visuales del virus GLRV, y plantas sin síntomas. Las uvas se vinificaron, en total 56 tanques, 28 son testigos y 28 provenían de plantas afectadas. Los vinos se sometieron a análisis de rutina. Se determinó el perfil antocianas por HPLC. El análisis de caracterización varietal de perfil de antocianas y ácido shikimico, corroboró que el perfil no ha variado. La incidencia de GLRV tiene un claro efecto negativo en la calidad de uvas.
\end{abstract}

\section{Introducción y antecedentes}

Los Virus: Grape Leaf Roll Virus (GLRV) y Grape Fan Leaf Virus (GFLV), ocasionan severas enfermedades en viñedos muy difundidos en el mundo vitivinícola. En Argentina dichas enfermedades se reportaron en el año 1997 [1] y sus síntomas han sido ampliamente descriptos. El impacto que tiene Grape Leaf Roll Virus (GLRV) se produce fundamentalmente sobre el rendimiento, ocasionando disminuciones de hasta un $70 \%$ en la producción. Además, genera retardos en la maduración, disminución en el contenido de azúcares y alteraciones en el color de las bayas. En las plantas, ocasiona reducción en: superficie foliar, clorofila y capacidad fotosintética. [2,3].

Al igual que todas las enfermedades en vegetales, el desarrollo de GLRV y sus efectos en la producción, son el resultado de la interacción entre el genotipo del huésped, el genotipo del patógeno y el ambiente en que se encuentra la planta (entendiéndose por ambiente: las condiciones climáticas, de suelo, de cultivo, ocurrencia de otros estrés, etc.). De esta manera, los daños reportados son muy variables, siendo siempre más severos en variedades tintas y de ciclo tardío.

Se ha descripto que la infección con Leaf Roll Virus en las variedades Riesling y Zinfandel no modifica parámetros vegetativos ni de producción, como: peso de poda y volumen de cosecha, tampoco acidez del mosto, sí modifica: porcentaje de sólidos solubles (grados brix) del mismo [4,5]. Por otro lado, en Pinot noir, sí se observaron disminuciones significativas en el volumen de cosecha y en el porcentaje de sólidos solubles del mosto,

a e-mail: d5cobos@yahoo.com.ar comparando plantas infectadas y sanas. Uno de los efectos más perjudiciales es su incidencia en la acumulación en uva de sustancias asociadas a características organolépticas del vino, como: antocianas y polifenoles [6].

En Argentina, el cv. Bonarda está entre las tres variedades tintas más importantes, representando un 9,23\% de las uvas ingresadas a establecimientos elaboradores de vinos y mostos. Su producción en el año 2011-2012 fue de 2.007.025 quintales, superada solamente por el cv. Malbec con $13,02 \%$ y 2.831 .030 quintales [7].

En Mendoza, la producción de uvas del cultivar Bonarda es de 1.620.018 quintales representando un $17,53 \%$ de la producción total de uvas ingresadas en el año 2012, para elaboración de vinos y mostos [8].

La variedad Bonarda, presenta ciclo vegetativo largo y los daños ocasionados por los virus son más severos en variedades tintas con esta característica. Entre los síntomas más importante se destaca el enrollamiento de la lámina foliar hacia la cara abaxial. En los cultivares tintos, el limbo foliar presenta una notable coloración violácea, conservando las nervaduras de color verde. En las variedades blancas se presenta una leve clorosis internerval [9]. Los síntomas se observan en la planta entera generalmente, las hojas basales suelen ser afectadas en primer lugar.

En Argentina, actualmente se determina el varietal de los vinos tintos, mediante el análisis del perfil de las antocianas en los vinos y del ácido shiquímico. El Instituto Nacional de Vitivinicultura cuenta con una base de datos de estos perfiles de antocianas y del contenido de ácido shiquímico de vinos elaborados con variedades de origen indudable, de todas las zonas vitivinícolas de Argentina.

This is an Open Access article distributed under the terms of the Creative Commons Attribution License 4.0, which permits unrestricted use, distribution, and reproduction in any medium, provided the original work is properly cited. 
Las variables utilizadas son nueve antocianas, la suma de acetilados y cumarilados y el cociente entre acetilados y cumarilados.

Estas variables están distribuidas en los siguientes grupos:

Grupo I:

Delfinidin 3 glucósido

Cyanidin 3 glucósido

Petunidin 3 glucósido

Peonidin 3 glucósido

Malvidin 3 glucósido

Grupo II:

Peonidin 3 acetil glucósido

Malvidin 3 acetil glucósido

Grupo III:

Peonidin 3 cumarilglucósido

Malvidin 3 cumarilglucósido

Suma grupo II + III:

Grupo acetilados + cumarilados

Razón grupo II/III:

Grupo acetilados / cumarilados

\section{Objetivos}

Evaluar calidad enológica y caracterización varietal de vinos cv. Bonarda, elaborados a partir de plantas con sintomatología visual de Grapevine Leaf Roll Virus, en contraposición con vinos elaborados con plantas visualmente sanas, cosechadas en cuatro zonas vitícolas de Mendoza, Argentina.

\section{Materiales y métodos}

\section{Toma de muestras}

Para la toma de muestras se seleccionaron viñedos de Bonarda con conocida presencia de GLRV en los siguientes oasis productivos: Zona norte (Costa de Araujo, Lavalle), Zona este (Alto Verde, Palmira, San Martin) (Mundo nuevo, Junín), Zona Alta (Ugarteche, Lujan de Cuyo), Zona Sur (La arboleda, Cordón del Plata, Tupungato) referidas a la posición del oasis con respecto al Rio Mendoza, Tabla 1. El diseño experimental del ensayo consistió en un muestreo dirigido no probabilístico. De cada viñedo seleccionado, se cosecharon uvas que provenían de: plantas visualmente infectadas con virus (V) y de plantas visualmente sanas $(\mathrm{S})$, ubicadas dentro de la misma hilera y separadas entre sí, por 10 plantas. Se elaboraron 56 vinificaciones, 28 provenientes de racimos sanos y 28 provenientes de racimos enfermos.

\section{Microvinificaciones}

Se efectuaron microvinificaciones empleando para cada una de ellas $9 \mathrm{Kg}$ de uvas. Para la elaboración de vinos se respetaron las mismas condiciones de vinificación empleadas para la elaboración de vinos de origen
Tabla 1. Resumen de toma de muestras.

\begin{tabular}{|l|l|l|l|}
\hline Departamento & Localidad & Plantas (V) & Plantas (S) \\
\hline Lavalle & Costa de Araujo & 5 (cinco) & 5 (cinco) \\
\hline San Martin & Alto Verde & $5($ cinco) & 5 (cinco) \\
\hline San Martin & Palmira & $5($ cinco) & $5($ cinco) \\
\hline Lujan de Cuyo & Ugarteche & $5($ cinco) & 5(cinco) \\
\hline Tupungato & La Arboleda & 3(tres) & 3(tres) \\
\hline Tupungato & Cordón del Plata & 3(tres) & 3(tres) \\
\hline Junín & Mundo Nuevo & 2(dos) & 2(dos) \\
\hline
\end{tabular}

indudable en INV. Estos vinos son el origen del banco de datos utilizados para determinar la caracterización varietal. Las uvas cosechadas se molieron manualmente. y se encubaron en tanques de 9 litros, se sulfitaron, se inocularon con levaduras secas activas comerciales y se fermentaron a $24^{\circ} \mathrm{C}$, realizando bazuqueos diarios hasta sequedad. La cinética de la fermentación, se determinó por diferencia de pesada. Al final de la fermentación, se realizaron análisis de rutina previo al fraccionamiento. Se dosificó anhídrido sulfuroso, con el objeto de impedir degradación biológica ácida. (Fermentación malo láctica), se estabilizaron los vinos, se filtraron y se fraccionaron en botellas que se conservaron para su análisis posterior.

\section{Método analítico}

Se realizaron diferentes ensayos físico-químicos en los laboratorios del Instituto Nacional de Vitivinicultura, para determinar las siguientes variables: Sólidos solubles en bayas: con uso de refractómetro [10], pH, Alcohol [11] y acidez total [12] en vinos: por métodos oficiales argentinos.

Índice de color en vinos: Se usó espectrofotómetro Shimadzu, con cubetas de $1 \mathrm{~mm}$ de paso óptico y lecturas a $420 \mathrm{~nm}$ y $520 \mathrm{~nm}$ [13].

Perfil de antocianas: Mediante inyección directa del vino en Cromatógrafo Líquido de Alta Resolución (HPLC), con fase reversa (fases móviles constituidas por mezclas de solvente polares), columna LiChrospher $100 \mathrm{RP} 18$ (5 um) a $40^{\circ} \mathrm{C}$ y detector UV con Arreglo de Diodos, desarrollando un sistema binario, con gradiente de fases móviles (Agua /Acido Fórmico / Acetonitrilo). $[14,15]$.

\section{Métodos estadísticos}

El procesamiento estadístico de datos se llevó a cabo mediante análisis de la varianza aplicado a cada variable. En las variables con diferencias significativas entre factores se utilizó análisis discriminante de medias y para las medias de las interacciones, el Test de Tukey HSD, con nivel mínimo de significancia $\mathrm{P}=0,05$. Se empleó Statgraphics plus 4.0 software program.

\section{Resultados}

Las bayas procedentes de plantas con virus, tuvieron menor contenido en sólidos solubles $\left({ }^{\circ}\right.$ Brix), que las bayas procedentes de plantas sanas. Los vinos obtenidos a 
Medias y $95,0 \%$ de Tukey HSD

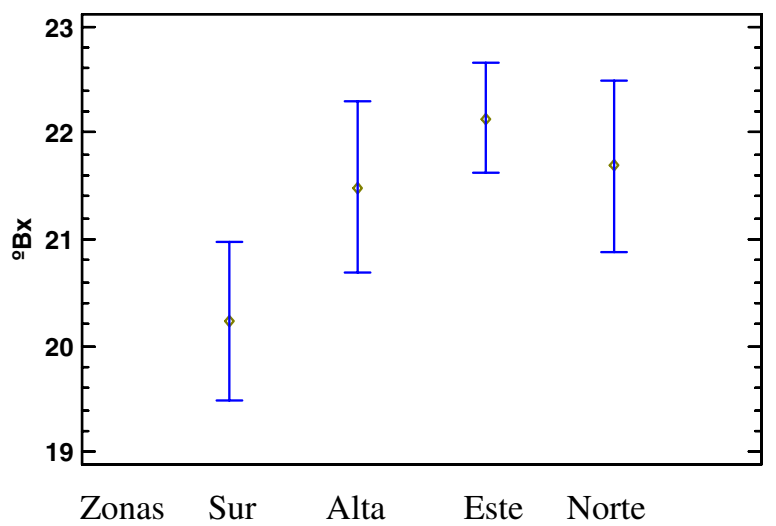

Figura 1. Diferenciación de las 4 zonas, respecto al contenido de sólidos solubles ( ${ }^{\circ}$ Brix $)$.

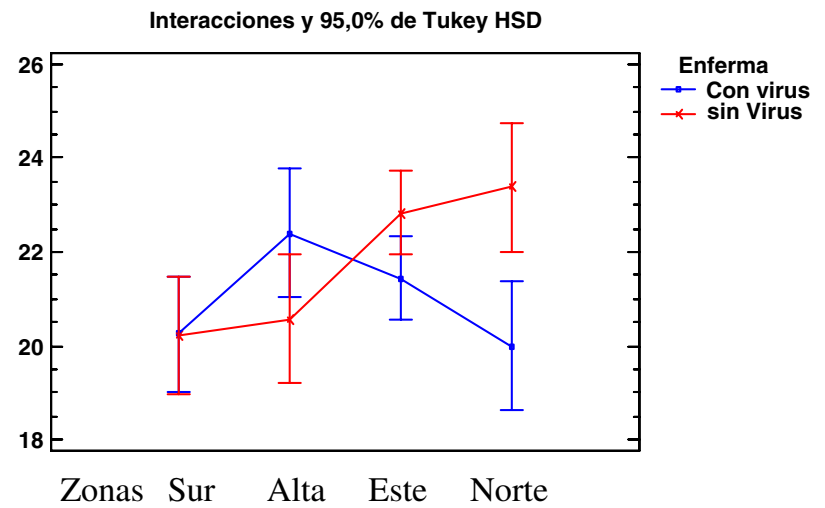

Figura 2. Diferenciación en sólidos solubles (grados Brix), de plantas con síntomas y plantas asintomáticas.

partir de plantas enfermas, presentaron menor graduación alcohólica, mayor $\mathrm{pH}$, menor acidez total y menor Índice de Color que los vinos obtenidos de plantas sanas. Los resultados manifestaron, que las zonas se diferencian en relación a dichas variables y que existen diferencias significativas en la interacción entre, las variables pertenecientes a las distintas zonas y los vinos obtenidos a partir de plantas sanas y enfermas. El análisis varietal del perfil de antocianas y ácido shiquímico, determinó que los vinos procedentes de plantas con virus no modificaron el perfil varietal.

\section{Sólidos Solubles en bayas ( ${ }^{\mathrm{Brix}}$ )}

Mediante análisis estadístico, se observa que se diferencian las zonas en estudio, respecto a la acumulación de sólidos solubles en las bayas, Fig. 1.

\section{Sólidos solubles en bayas de plantas con síntomas y asintomáticas:}

Las diferencias en el contenido de sólidos solubles entre plantas con síntomas de virus y sin ellos, se presentaron en las Zonas Norte y en menor proporción en las zonas Alta y Este, Fig. 1.

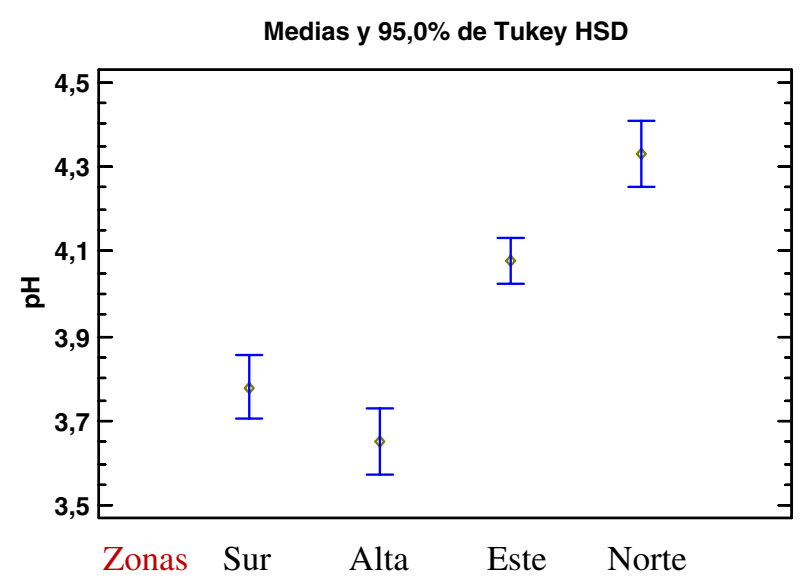

Figura 3. Diferenciación de las zonas productoras por el valor obtenido en los $\mathrm{pH}$ de los vinos.

Tabla 2. Pruebas de Múltiple Rangos para pH por Región referida al Rio Mendoza.

Método: 95,0 porcentaje Tukey HSD

\begin{tabular}{|l|l|l|l|l|}
\hline $\begin{array}{l}\text { Región referida } \\
\text { al Rio Mendoza }\end{array}$ & Casos & Media LS & Sigma LS & $\begin{array}{l}\text { Grupos } \\
\text { Homo- } \\
\text { géneos }\end{array}$ \\
\hline $\begin{array}{l}\text { Zona Alta Rio } \\
\text { Mendoza }\end{array}$ & 10 & 3,66 & 0,0434058 & $\mathrm{X}$ \\
\hline $\begin{array}{l}\text { Zona Sur - } \\
\text { Tupungato }\end{array}$ & 12 & 3,775 & 0,0396239 & $\mathrm{X}$ \\
\hline Zona Este & 24 & 4,07797 & 0,0281161 & $\mathrm{X}$ \\
\hline Zona Norte & 10 & 4,33 & 0,0434058 & $\mathrm{X}$ \\
\hline
\end{tabular}

\begin{tabular}{|l|l|l|l|}
\hline Contraste & Sig. & Diferencia & + - Limites \\
\hline $\begin{array}{l}\text { Zona Sur - Zona Alta } \\
\text { Rio Mendoza }\end{array}$ & & 0,115 & 0,156424 \\
\hline $\begin{array}{l}\text { Zona Sur - } \\
\text { Zona Este }\end{array}$ & $*$ & $-0,302972$ & 0,129314 \\
\hline $\begin{array}{l}\text { Zona Sur - } \\
\text { Zona Norte }\end{array}$ & $*$ & $-0,555$ & 0,156424 \\
\hline $\begin{array}{l}\text { Zona Alta Rio Mendoza - } \\
\text { Zona Este }\end{array}$ & $*$ & $-0,417972$ & 0,137646 \\
\hline $\begin{array}{l}\text { Zona Alta Rio Mendoza - } \\
\text { Zona Norte }\end{array}$ & $*$ & $-0,67$ & 0,16338 \\
\hline $\begin{array}{l}\text { Zona Este - } \\
\text { Zona Norte }\end{array}$ & $*$ & $-0,252028$ & 0,137646 \\
\hline
\end{tabular}

\section{$\mathrm{pH}$}

Los vinos obtenidos presentaron diferentes valores de $\mathrm{pH}$, permitiendo separar claramente las zonas de origen de las uvas con que fueron elaborados, Fig. 3.

Asimismo los valores obtenidos mostraron diferencias estadísticamente significativas entre las zonas, las únicas dos regiones que no presentaron niveles diferentes fueron Zona Sur con respecto a Zona Alta, Fig. 4. Tabla 2

Cabe destacar que dentro de las regiones vitivinícolas argentinas, en los oasis de este estudio, es una práctica habitual y necesaria la corrección de acidez. Sin embargo la zona Sur (del Alto Valle de Tupungato), debido a tres 


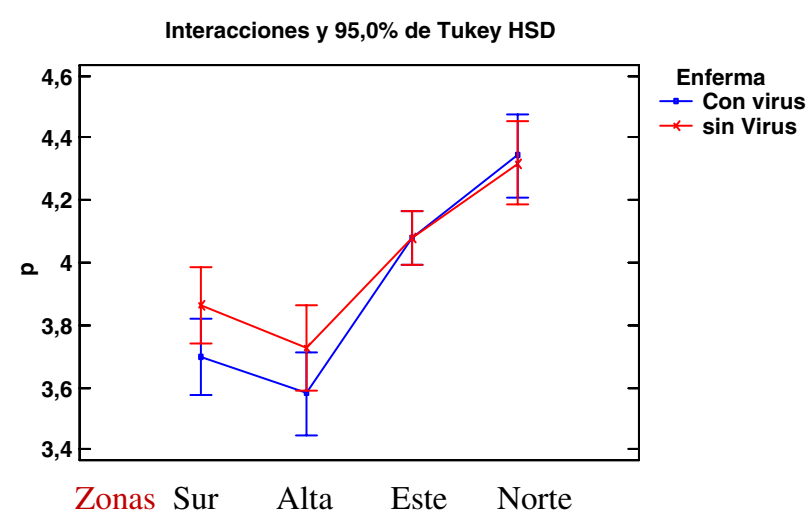

Figura 4. Diferenciación en los valores de $\mathrm{pH}$, de los vinos.

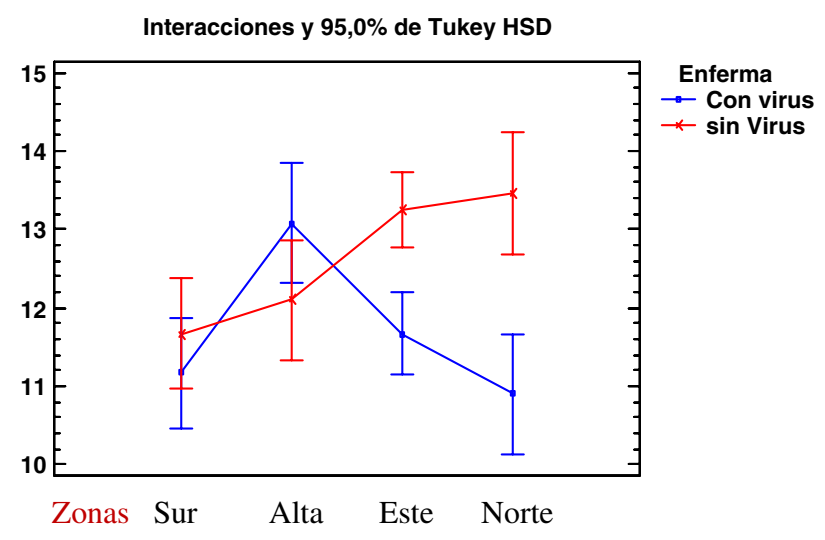

Figura 5. Diferenciación de zonas geográficas, por producción de alcohol en los vinos.

índices: helio-térmico, de frio nocturno y de sequia, es la región más privilegiada en este parámetro enológico [16].

\section{Alcohol (\%vol/vol)}

También el alcohol producido en los vinos que provienen de vides enfermas y sanas, permite diferenciar las zonas. En las zonas Sur y Alta, si bien hay diferencias, éstas no son estadísticamente significativas. En las zonas Este y Norte las diferencias sí lo son, Fig. 5. Tabla 3.

\section{Acidez total (en g/l de ácido tartárico)}

Las diferencias entre los valores obtenidos en acidez total permiten diferenciar las distintas zonas geográficas, hay diferencias entre las zonas Sur y Alta con respecto a las zonas Este y Norte, Fig. 6, Tabla 4.

Las diferencias entre los valores obtenidos en acidez total son más importantes entre las distintas zonas, presentando diferencias significativas entre las zonas Sur y Alta con respecto a las zonas Este y Norte, debido al estado sanitario de las plantas, hay diferencias, pero no son estadísticamente significativas en tres de las zonas.

\section{Índice de color}

Este parámetro, refleja claramente como la Zona Alta se diferencia de las otras zonas, cabe mencionar que es la
Tabla 3. Pruebas de Múltiple Rangos para Alcohol por Región referida al Rio Mendoza.

Método: 95,0 porcentaje Tukey HSD

\begin{tabular}{|l|l|l|l|l|}
\hline $\begin{array}{l}\text { Región referida } \\
\text { al Rio Mendoza }\end{array}$ & Casos & Media LS & Sigma LS & $\begin{array}{l}\text { Grupos } \\
\text { Homo- } \\
\text { géneos }\end{array}$ \\
\hline Zona Sur & 12 & 11,4167 & 0,223235 & $\mathrm{X}$ \\
\hline Zona Norte & 10 & 12,18 & 0,244542 & $\mathrm{XX}$ \\
\hline Zona Este & 24 & 12,4587 & 0,158402 & $\mathrm{X}$ \\
\hline $\begin{array}{l}\text { Zona Alta } \\
\text { Rio Mendoza }\end{array}$ & 10 & 12,59 & 0,244542 & $\mathrm{X}$ \\
\hline
\end{tabular}

\begin{tabular}{|c|c|c|c|}
\hline Contraste & Sig. & Diferencia & +/- Limites \\
\hline $\begin{array}{l}\text { Zona Sur - Zona Alta } \\
\text { Rio Mendoza }\end{array}$ & & 0,115 & 0,156424 \\
\hline Zona Sur - Zona Este & $*$ & $-0,302972$ & 0,129314 \\
\hline Zona Sur - Zona Norte & * & $-0,555$ & 0,156424 \\
\hline $\begin{array}{l}\text { Zona Alta Rio } \\
\text { Mendoza - Zona Este }\end{array}$ & * & $-0,417972$ & 0,137646 \\
\hline $\begin{array}{l}\text { Zona Alta Rio } \\
\text { Mendoza - Zona Norte }\end{array}$ & * & $-0,67$ & 0,16338 \\
\hline Zona Este - Zona Norte & $*$ & $-0,252028$ & 0,137646 \\
\hline
\end{tabular}

Medias y $95,0 \%$ de Tukey HSD

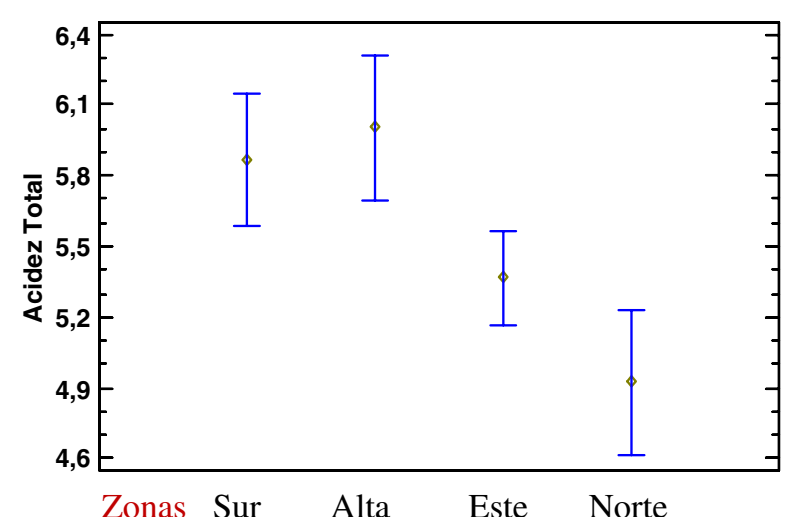

Figura 6. Diferenciación de zonas geográficas por sus valores de acidez total en los vinos.

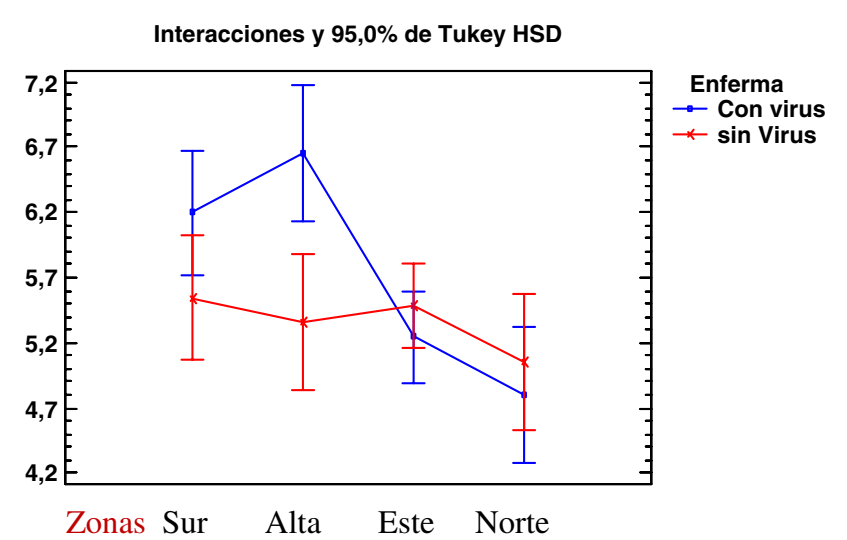

Figura 7. Diferenciación en los valores obtenidos en la acidez total de los vinos. 
Tabla 4. Pruebas de Múltiple Rangos para Acidez Total por Región referida al Rio Mendoza.

Método: 95,0 porcentaje Tukey HSD

\begin{tabular}{|l|l|l|l|l|}
\hline $\begin{array}{l}\text { Región referida } \\
\text { al Rio Mendoza }\end{array}$ & Casos & Media LS & Sigma LS & $\begin{array}{l}\text { Grupos } \\
\text { Homo- } \\
\text { géneos }\end{array}$ \\
\hline Zona Norte & 10 & 4,923 & 0,164752 & $\mathrm{X}$ \\
\hline Zona Este & 24 & 5,36794 & 0,106718 & $\mathrm{X}$ \\
\hline Zona Sur & 12 & 5,87 & 0,150398 & $\mathrm{X}$ \\
\hline $\begin{array}{l}\text { Zona Alta Rio } \\
\text { Mendoza }\end{array}$ & 10 & 6,005 & 0,164752 & $\mathrm{X}$ \\
\hline
\end{tabular}

\begin{tabular}{|l|l|l|l|}
\hline Contraste & Sig. & Diferencia & + /- Límites \\
\hline $\begin{array}{l}\text { Zona Sur - Zona } \\
\text { Alta Rio Mendoza }\end{array}$ & & $-0,135$ & 0,593728 \\
\hline $\begin{array}{l}\text { Zona Sur - Zona } \\
\text { Este }\end{array}$ & $*$ & 0,502063 & 0,490826 \\
\hline $\begin{array}{l}\text { Zona Sur - Zona } \\
\text { Norte }\end{array}$ & $*$ & 0,947 & 0,593728 \\
\hline $\begin{array}{l}\text { Zona Alta Rio } \\
\text { Mendoza - Zona } \\
\text { Este }\end{array}$ & $*$ & 0,637063 & 0,522453 \\
\hline $\begin{array}{l}\text { Zona Alta Rio } \\
\text { Mendoza - Zona } \\
\text { Norte }\end{array}$ & $*$ & 1,082 & 0,620129 \\
\hline $\begin{array}{l}\text { Zona Este - Zona } \\
\text { Norte }\end{array}$ & & 0,444937 & 0,522453 \\
\hline * Indica una diferencia significativa. & & \\
\hline
\end{tabular}

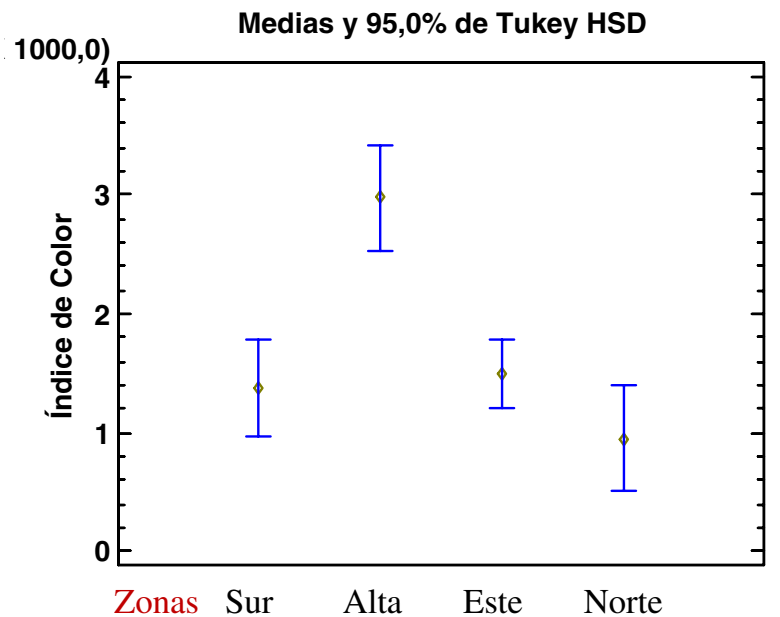

Figura 8. Diferenciación de las 4 zonas, en función de los valores hallados para el índice de color de los vinos.

única que posee riego por goteo con una estrategia definida con el objeto de elaborar vinos de alta gama, Fig. 8. Tabla 5.

La zona Alta, muestra claramente una diferencia entre el estado fitosanitario, en las restantes zonas las diferencias no son estadísticamente significativas, figura.

\section{Perfil de antocianas:}

La incidencia del virus Grapevine LeafRoll en el perfil de antocianas y ácido shikimico, en vinos obtenidos con uvas de vides con síntomas de la enfermedad y sin síntomas

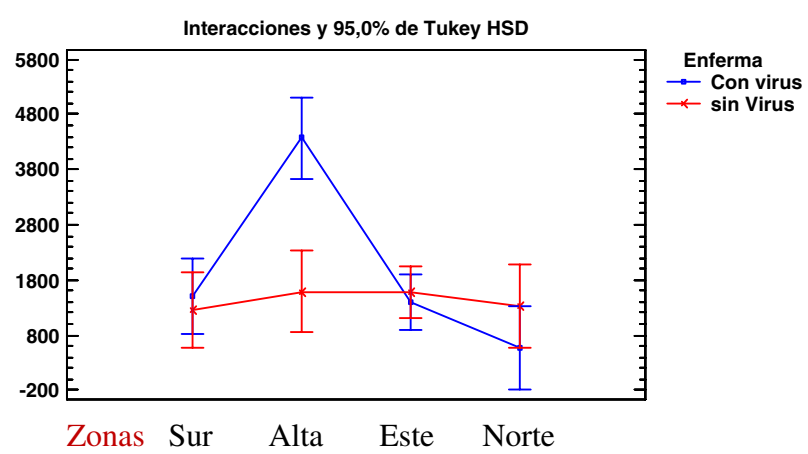

Figura 9. Diferenciación entre los índices de colores de los vinos.

Tabla 5. Pruebas de Múltiple Rangos para Índice de Color por Región referida al Rio Mendoza.

Método: 95,0 porcentaje Tukey HSD

\begin{tabular}{|l|l|l|l|l|}
\hline $\begin{array}{l}\text { Región referida } \\
\text { al Rio Mendoza }\end{array}$ & Casos & Media LS & Sigma LS & $\begin{array}{l}\text { Grupos } \\
\text { Homo- } \\
\text { géneos }\end{array}$ \\
\hline Zona Norte & 10 & 948,2 & 236,841 & $\mathrm{X}$ \\
\hline Zona Sur & 12 & 1384,08 & 216,205 & $\mathrm{X}$ \\
\hline Zona Este & 24 & 1490,67 & 153,414 & $\mathrm{X}$ \\
\hline $\begin{array}{l}\text { Zona Alta } \\
\text { Rio Mendoza }\end{array}$ & 10 & 2979,8 & 236,841 & $\mathrm{X}$ \\
\hline
\end{tabular}

\begin{tabular}{|l|l|l|l|}
\hline Contraste & Sig. & Diferencia & + /- Límites \\
\hline $\begin{array}{l}\text { Zona sur - Zona } \\
\text { Alta Rio Mendoza }\end{array}$ & $*$ & $-1595,72$ & 853,518 \\
\hline $\begin{array}{l}\text { Zona Sur - Zona } \\
\text { Este }\end{array}$ & & $-106,591$ & 705,59 \\
\hline $\begin{array}{l}\text { Zona Sur - Zona } \\
\text { Norte }\end{array}$ & $*$ & 1489,13 & 751,055 \\
\hline $\begin{array}{l}\text { Zona Alta Rio } \\
\text { Mendoza - Zona } \\
\text { Este }\end{array}$ & $*$ & 2031,6 & 891,47 \\
\hline $\begin{array}{l}\text { Zona Alta Rio } \\
\text { Mendoza - Zona } \\
\text { Norte }\end{array}$ & & 542,475 & 751,055 \\
\hline $\begin{array}{l}\text { Zona Este - Zona } \\
\text { Norte }\end{array}$ & & 55,518 \\
\hline Indica una diferencia significativa. & \multicolumn{2}{l}{} \\
\hline
\end{tabular}

para la caracterización varietal de los vinos, los resultados obtenidos mostraron que se conserva el perfil de antocianas y la identificación varietal, Figs. 10-19.

\section{Conclusiones}

Las conclusiones de las diferentes experiencias llevadas a cabo en los ensayos de vinificación obtenidos a partir de uvas que presentaban síntomas visuales de virus y asintomáticas. Se pueden resumir las siguientes:

1- Se verificó en vitis vinífera cv Bonarda, la incidencia del virus Grapevine LeafRoll sobre el detrimento de la calidad de uvas y vinos elaborados a partir de ellas. (Sólidos solubles, pH, Alcohole e índice de color).

2- Se evaluó la incidencia del virus Grapevine LeafRoll en el perfil de antocianas y ácido shikimico, en vinos obtenidos con uvas de vides con síntomas de la enfermedad y sin síntomas, mediante el análisis por cromatografía 


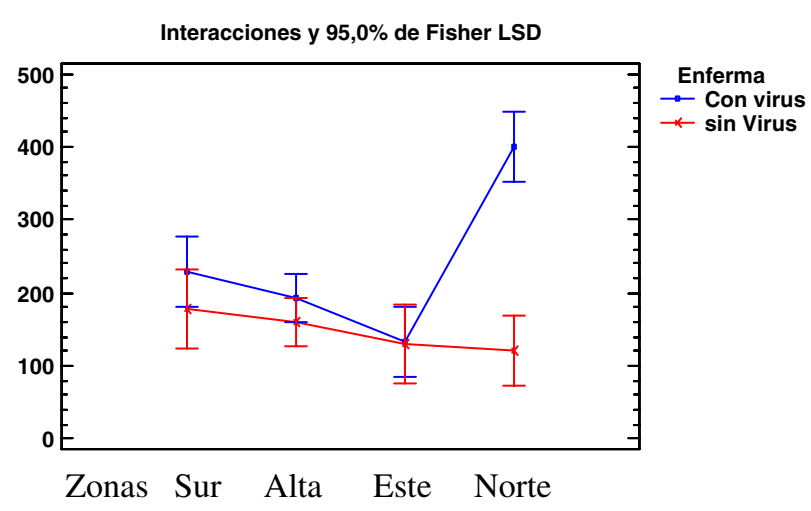

Figura 10. Diferenciación en la concentración de Antocianas totales expresadas en $\mathrm{mg} / \mathrm{l}$ de Malvidinas, de los vinos.

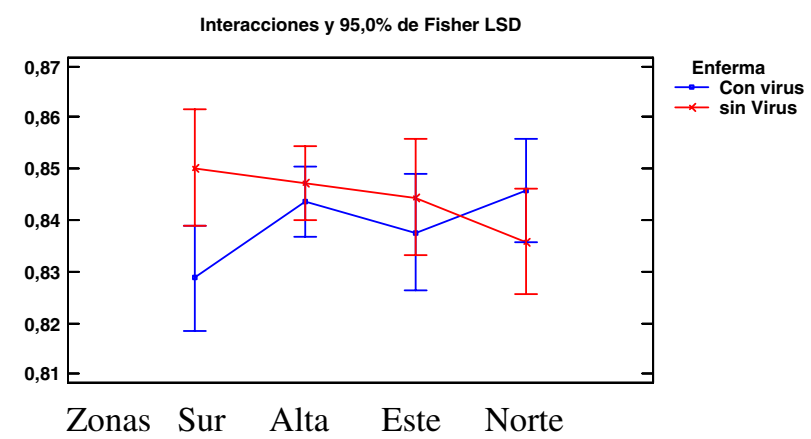

Figura 11. Diferenciación en el porcentaje del grupo de Glucosidados de los vinos.

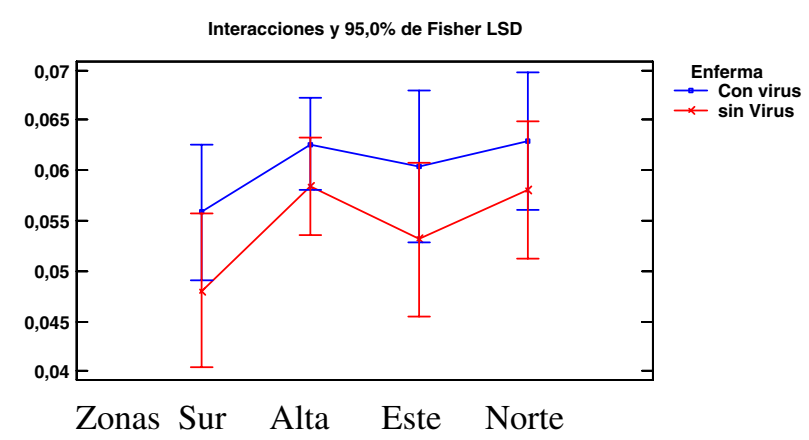

Figura 12. Diferenciación en el porcentaje del grupo de los Cumarilados, de los vinos.

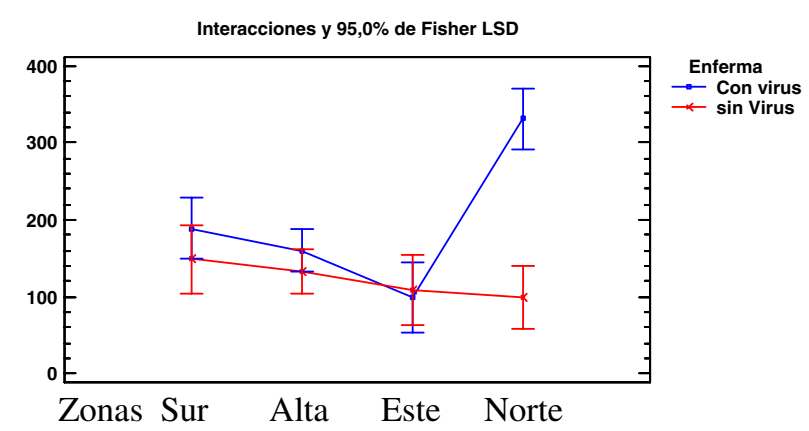

Figura 13. Diferenciación en la concentración de Antocianas azulinas, de los vinos.

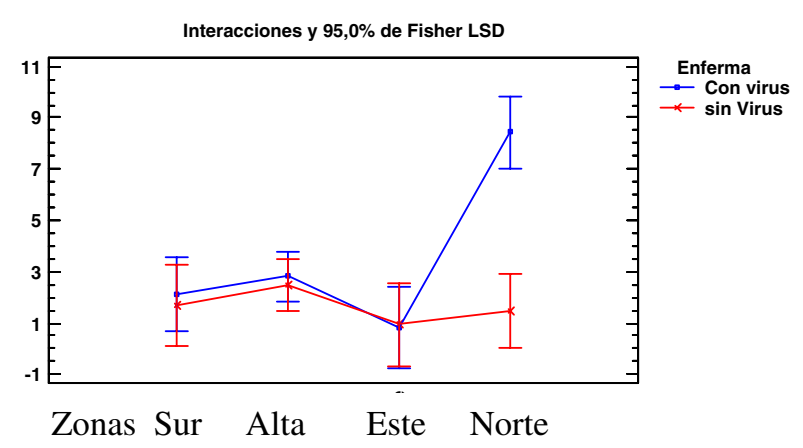

Figura 14. Diferenciación en la concentración de Antocianas rojizas, de los vinos.

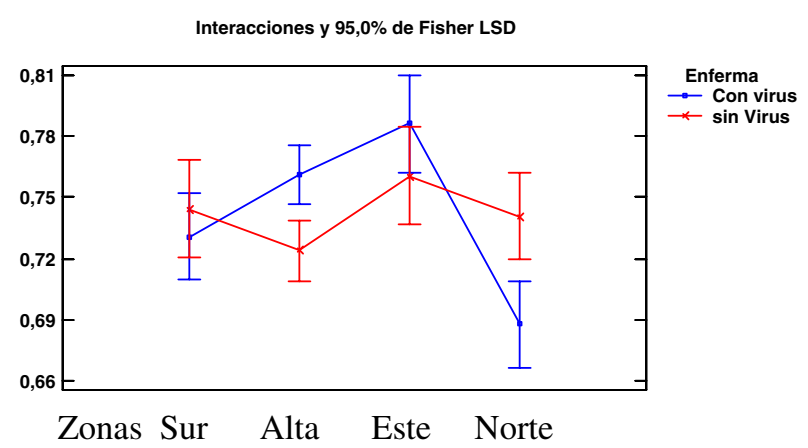

Figura 15. Diferenciación en el grupo Malvidin -3e- Acetil Glucosidado de los vinos.

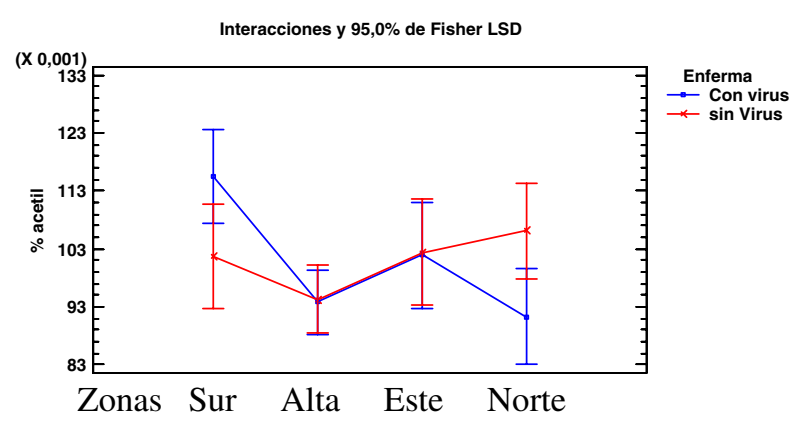

Figura 16. Diferenciación en los porcentajes del grupo de Acetilados, de los vinos.

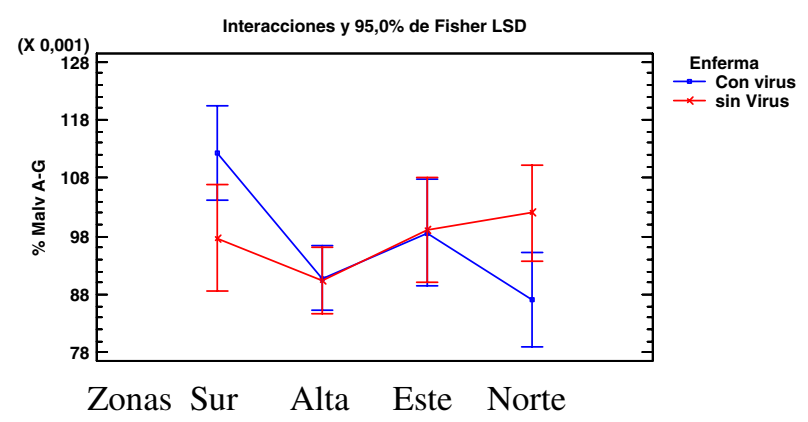

Figura 17. Diferenciación en el porcentaje de Malvidin -3- Acetil Glucosidados, de los vinos. 


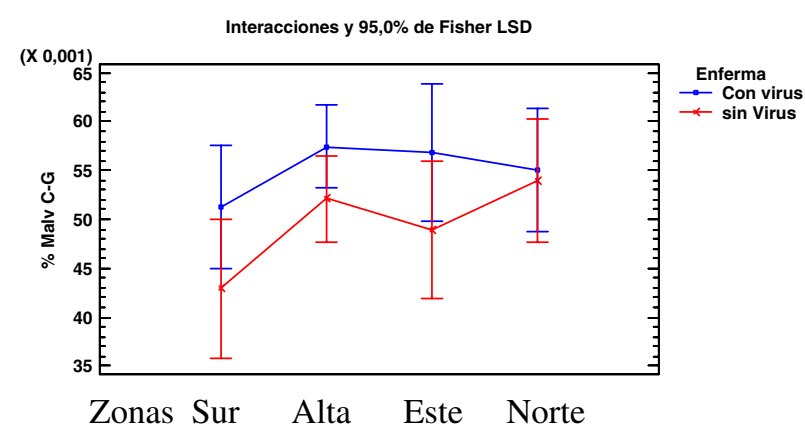

Figura 18. Diferenciación en el porcentaje de Malvidin -3Cumaril Glucosidados de los vinos.

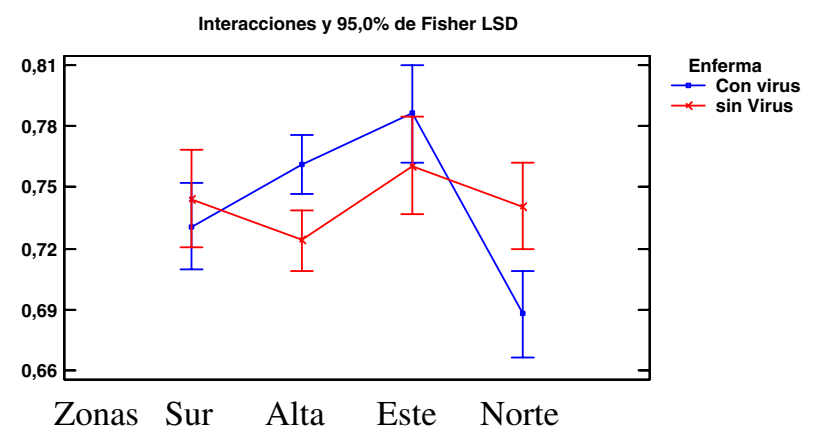

Figura 19. Diferenciación en los porcentajes del Malvidin -3Glucosido de los vinos.

liquida de alta resolución de fase reversa, método oficial adoptado por la Argentina (Instituto Nacional de Vitivinicultura), los resultados obtenidos mostraron que se conserva el perfil de antocianas y la identificación varietal, aun con las diferencias exhibidas entre plantas con síntomas y sin síntomas.

A los señores: Lic. Manzano, Humberto y Enólogo Pascualetti, Gabriel. Y a los diferentes productores que colaboraron.

\section{Referencias}

[1] O. Gracia, E. Vega, PA.Worlock. Detección de Virosis de la vid en Mendoza (Argentina) con la técnica ELISA. XXII Congres de Vigne et du Vin, Buenos Aires, Argentina (1997)

[2] J. Lee, R. Martin.: Influence of grapevine leafroll associated viruses (GLRaV-2 and-3) on the fruit composition of Oregon Vitis vinífera L. cv. Pinot noir: Free amino acids, sugars, and organic acids. Food Chemistry., 7pp. 99 a 105(2009)

[3] J. Moutinho -Pereira, C. Correia, B. Goncalves, E. Bacelar, J. Coutinho, H Ferreira.: Impacts of Leafroll-associated viruses (GLRaV-1and -3 ) on the physiology of the Portuguese grapevine cultivar" Touriga Nacional" growing under field conditions. Ann Appl Biol., 160. 13 pp. 237-249 (2012)

[4] J. Wolpert, E. Vilas.: Estimating Vineyard Yields: Introduction to a simple, two-step method., Am. J. Enol. Vitic., 43, N4. 5 pp. 384 a 388. (1992).

[5] J. Wolpert, E. Vilas.: Effect of Mild Leafroll Disease on Growth, Yield, and Fruit maturity indices of Riesling and Zinfandel. Am. J. Enol. Vitic., 43, $\mathrm{N}^{\circ} 4$. 3 pp. 367 a 369. (1992)

[6] J. Lee, R. Martin.: Influence of grapevine leafroll associated viruses (GLRaV-2 and-3) on the fruit composition of Oregon Vitisvinífera L. cv. Pinot noir: Phenolics. Food Chemistry., 8pp. 889 a 896.(2009)

[7] Instituto Nacional de Vitivinicultura, Estadística Vitivinícola Argentina. Segunda parte. 2 pp. 9 a 10. (2012)

[8] Instituto Nacional de Vitivinicultura, Estadística Vitivinícola Argentina. Segunda parte. 1 pp. 70. (2012)

[9] D. Mundy.: Virus effects on Sauvignon blanc wine quality: Progress report 2006.Marlborough Wine Research Centre. 17 pp. (2006)

[10] Instituto Nacional de Vitivinicultura República Argentina. Resolución C1- 2004

[11] Instituto Nacional de Vitivinicultura. República Argentina. Resolución $\mathrm{N}^{\circ} \mathrm{C} .123$-1985.(1985)

[12] Instituto Nacional de Vitivinicultura. República Argentina. Resolución $\mathrm{N}^{\circ}$ C.12. 9/8/1965. Dirección Nacional de Química.(1965)

[13] Y. Glories, La Couleur des vins rouges. II partie. Mesure, origine et interpretatión. Com Vigne Vin, 18, 253 a 271(1984)

[14] H. Otteneder and R. Marx. LandesuntersuchungsamtRheinland-Pfalz, Institut fur Lebensmittelchemie Trier, Maximinerach 11 a, D-54295 Trier

[15] Instituto Nacional de Vitivinicultura, República Argentina Resolución $\mathrm{N}^{\circ} \mathrm{C}$ 23- 2006. Perfil de antocianas (Otteneder et al., 2001) y ácido Shikimico.(2006)

[16] C. Catania, S. Avagnina de del Monte, E. Uliarte, R. del Monte, J. Tonietto.: El clima vitícola de las regiones productoras de uvas para vinos de Argentina. Embrapa Uva e Vinho- INTA., 4pp.37 a 40(2007) 